\title{
Navigation System for Foreign Tourists in Japan
}

\author{
Kayoko Yamamoto \\ Graduate School of Information Systems, National University of Electro-Communications, Tokyo 182-8585, Japan
}

\begin{abstract}
The present study aimed to design, develop, operate and evaluate a sightseeing navigation system in order to support foreign tourists' efficient acquisition of sightseeing spot information in Japanese urban tourist areas, about which a variety of information is transmitted, by enabling information to be accumulated, shared and recommended. The system was developed by integrating Web-GIS (Geographic Information Systems), SNS (Social Networking Services) as well as the recommendation system into a single system. The system used the non-language information such as signs, marks and pictograms in addition to English information, and displayed sightseeing spot information and conduct navigation on 2D and 3D digital maps of the Web-GIS. Additionally, the system was operated for two weeks in the central part of Yokohama city in Kanagawa Prefecture, Japan, and the total number of users was 54. Based on the results of the web questionnaire survey, all of the specific functions are highly evaluated, and the usefulness of the system when sightseeing was excellent. From the results of the access analysis of users' log data, it is evident that it can be said that the system was mainly used before sightseeing and users confirm their favorite sightseeing spots and made their tour planning in advance, using 2D and 3D digital maps.
\end{abstract}

Key words: Sightseeing navigation system, Web-GIS (Geographic Information Systems), SNS (Social Networking Service), recommendation system, non-language information, foreign tourists.

\section{Introduction}

In recent years, the transformation of Japan to an information-intensive society is progressing, and a variety of information is being transmitted using the internet. Similarly, a variety of information is also being transmitted using the internet in the field of tourism, and the internet has become a primary information source for planning tourist trips and searching for information about the area of a destination. However, due to the large amount of information, and the variety of types of information, it is difficult for users to appropriately select and acquire necessary information by themselves. In particular, the amount of information submitted and made public about sightseeing spots in urban areas is very large compared to that for regional sightseeing spots, and it is difficult for people who do not have much knowledge of or acquaintance with the places concerned to efficiently obtain information necessary

Corresponding author: Kayoko Yamamoto, Ph.D., associate professor, research fields: spatial information science and urban planning. for taking tourist trips. As many who visit sightseeing spots do not have a good sense of locality, they get to know the route to their destination by means of guidebooks using paper maps. However, carrying around maps is inconvenient, and because users must look up the route to their destination by constantly checking their current location on the map, this time-consuming process may reduce their desire to sightsee.

On the other hand, "Visit Japan Campaign" was started in 2003, and the number of foreign tourists visiting Japan reached 10 million in 2013. Additionally, since the Tokyo Olympic and Paralympic Games will be held in 2020, it is anticipated that the number of foreign tourists visiting Japan will further continue increasing. However, in Japan, the most serious dissatisfaction of foreign tourists concerning tourism industry is that there are few foreign language services. Therefore, it is essential to response to their requests of sightseeing services in Japan. Based on the background mentioned above, the present study aims to uniquely develop a sightseeing navigation system which integrates a 
Web-GIS (Geographic Information Systems), an SNS (Social Networking Services) and a recommendation system, and is designed for foreign tourists, in order to support foreign tourists' efficient acquisition of sightseeing spot information in Japanese urban tourist areas, about which a variety of information is transmitted, by enabling information to be accumulated, shared and recommended. Moreover, premising foreign tourists' use, the system in the present study is designed and developed.

Regarding the operation target area, the central part of Yokohama city in Kanagawa Prefecture, Japan, was selected. One reason for this selection is that it has many foreign tourists visit, as it is a popular urban sightseeing area, and that it is difficult for foreign tourists to efficiently obtain information due to the large amount of information submitted and released. The second is that sightseeing spots can be recommended according to the user preferences using the system, as there is a variety of sightseeing spots.

\section{Related Work}

The system in the present study was developed by integrating plural systems such as Web-GIS, SNS as well as the recommendation system into a single system. Therefore, the present study is related to 3 study fields, namely: (1) studies regarding tourism support systems and methods; (2) studies regarding recommendation systems and methods for sightseeing spots and (3) studies regarding social media GIS.

In (1) studies regarding tourism support systems and methods, Ishizuka, J., et al. [1] proposed a similarity search method for the movement tracking data of tourists obtained from their location data and its text information. Kurata, Y. [2] developed an automatic generation system for sightseeing courses using Web-GIS and GA (Genetic Algorithm). Kawamura, H. [3] proposed the use of standard tags related to sightseeing on SNS, and set up a website to organize tourism information of Hokkaido on the Internet. Sasaki, J., et al. [4] gathered information concerning local resources and develop a system that supports the sightseeing activities of each user. Fujitsuka, T., et al. [5] used the pattern mining method which lists and extracts the time series action when touring sightseeing spots, and developed an outing plan recommendation system. Ueda, T., et al. [6] generated post-activity information from the sightseeing activities of the users, and developed a tourism support system which shares such information as prior information for other users. Okuzono, M., et al. [7] took into consideration the preferences of several people using photos, and proposed a system that recommends sightseeing spots. Fujita, S. and Yamamoto, K. [8] developed a navigation system using AR (Augmented Reality), Web-GIS and social media, in order to support sightseeing activities during normal occasions and evacuation in case of a disaster.

In (2) studies regarding recommendation systems and methods for sightseeing spots, Kurashima, T., et al. [9] as well as Van Canneyt, S., et al. [10] respectively proposed a travel route recommendation system and a sightseeing spot recommendation system using geotags from picture-sharing sites. Batet, M., et al. [11] developed a recommendation system of sightseeing spots using the multi-agent system. Uehara, H., et al. [12] extracted tourism information from the Internet, calculated the similarity between sightseeing spots from several feature vectors, and developed a system that recommends sightseeing spots. Shaw, B., et al. [13] took into consideration the location information and visit history of the users, and develop a system that presents a list of sightseeing spots near the user. Zhou, J. and Yamamoto, K. [14] develop a sightseeing spot recommendation system using AR, Web-GIS and SNS.

Additionally, studies related to POI (Point-of-Interest) recommendations among studies related to LBSN (Location-Based Social Networks) are also included in the same field of the present study. Representative examples include the POI recommendation system by $\mathrm{Yu}, \mathrm{C}$. C. and Chang, H., 
P. [15] which supports travel planning, the POI recommendation system by Noguera, J. M., et al. [16] which is based on current location information, and the POI recommendation system proposed by Baltrunas, M., et al. [17] which is based on location information and user preference. Ye, M., et al. [18] and Ying, E., et al. [19] proposed a POI recommendation system which is based on location information and user preferences as well as social networks. Bao, J., et al. [20] also proposed a recommendation system. Yuan, Q., et al. [21] proposed a POI recommendation method which takes into consideration time and space, while Liu, X., et al. [22] proposed a POI recommendation method which takes into consideration the changes in user preferences. Abe, S., et al. [23] developed a tourism information system with language-barrier-free interfaces, just targeting foreign visitors.

In (3) studies regarding social media GIS, Yanagisawa, T. and Yamamoto, K. [24] as well as Nakahara, H., et al. [25] developed an information sharing GIS, using Web-GIS, SNS and Wiki, with the purpose of storing and sharing information of the local community. Yamada, S. and Yamamoto, K. [26] and Okuma, T. and Yamamoto, K. [27] developed a social media GIS which strengthened the social media function of the information sharing GIS mentioned above. Based on such systems developed from preceding studies, Murakoshi, T., Yamamoto, K. and Fujita, S. [28, 29] developed a social media GIS supporting the continuous use of disaster information during normal occasions and in case of a disaster. Additionally, based on these social media GIS, Ikeda, T. and Yamamoto, K. [30] developed a social recommendation GIS to accumulate sightseeing spot information and recommend sightseeing spot information according to the preferences of each user. Moreover, referring to Ikeda, T. and Yamamoto, K. [30], Mizutani, Y. and Yamamoto, K. [31] developed a sightseeing spot recommendation system taking into account the change in circumstances of users.
Among the preceding studies in related fields as listed above, (1) (2) (3) support the tour planning and accumulating, sharing and recommending of sightseeing spot information for sightseeing activity support. However, the existing system developed in Japanese preceding studies just targeted Japanese, except for Abe, S., et al. [23] which took account foreign tourists' use. Additionally, the existing system developed in other preceding studies premised the use of English in addition to their native languages, and did not realize language-barrier-free interfaces. Against the above-mentioned preceding studies, the present study demonstrates the originality to develop a sightseeing navigation system, by integrating a Web-GIS, an SNS, and a recommendation system and targeting foreign tourists. Furthermore, the present study shows the usefulness to use the non-language information such as signs, marks and pictograms in addition to English information, and display sightseeing spot information and conduct navigation in an easy-to-understand manner on 2D and 3D digital maps of the Web-GIS.

\section{System Design}

\subsection{System Configuration}

The system of the present study is developed by means of a Web-GIS, an SNS, and a recommendation system, as shown in Fig. 1. The system enables to visualize location information and routes on $2 \mathrm{D}$ and 3D digital maps of the Web-GIS, accumulate and share sightseeing spot information, and communicate among users using SNS. Additionally, the system recommends sightseeing spots which meet users' preference using a recommendation system. Regarding navigation, information of the route to a single sightseeing spot from the current location of the user as well as routes for touring a group of sightseeing spots are provided.

\subsection{Target Information Terminals}

Though the system is meant to be used from PCs 


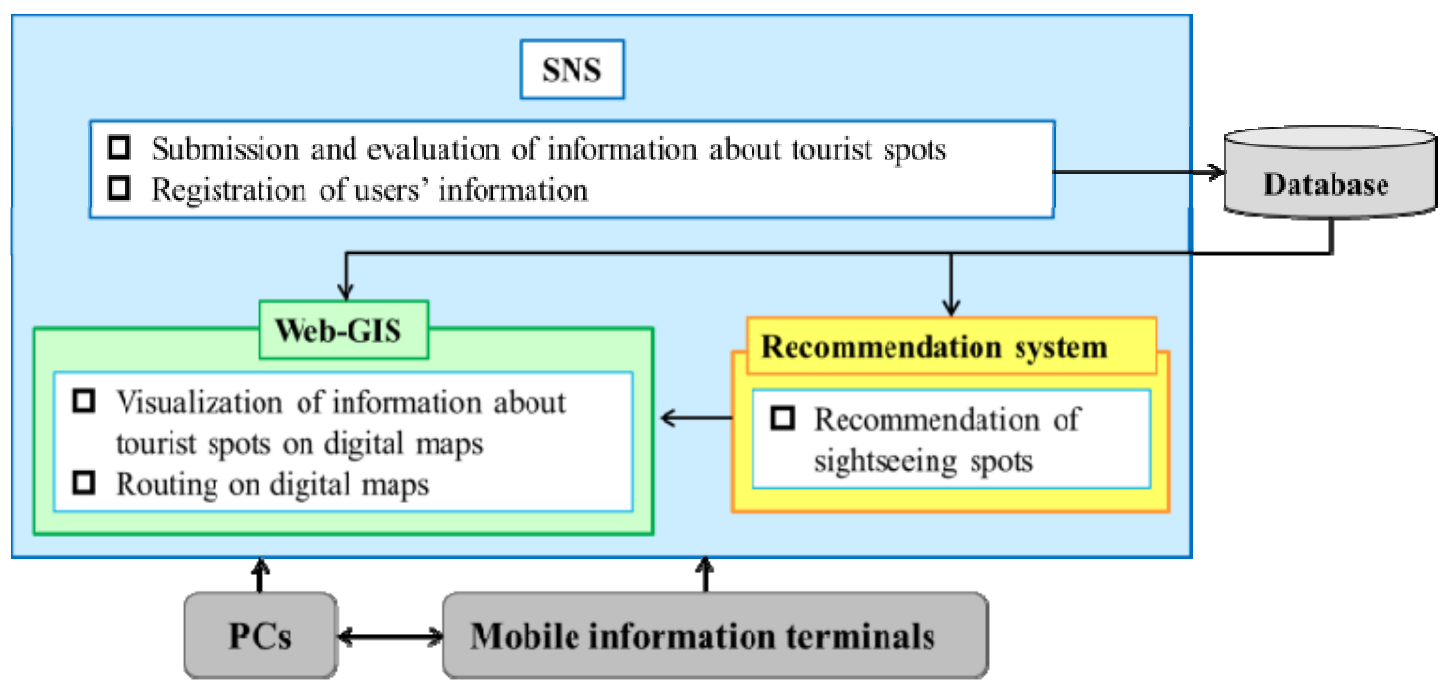

Fig. 1 System design of navigation system for foreign tourists.

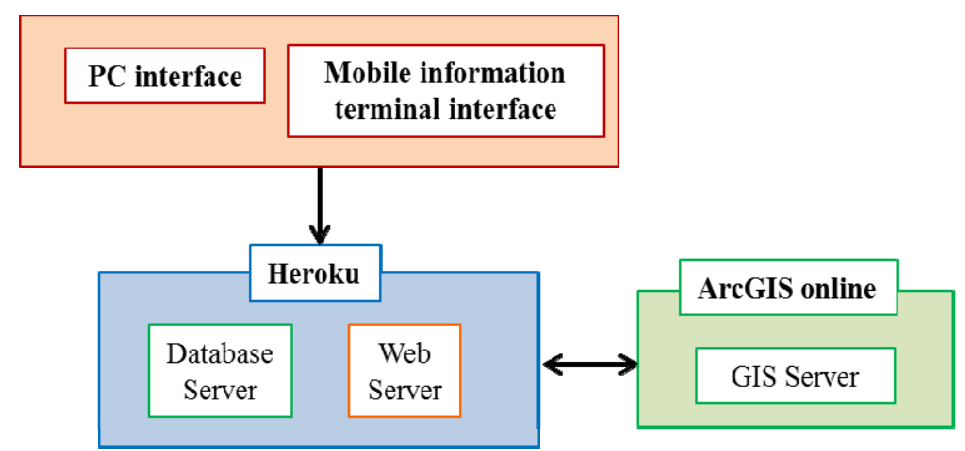

Fig. 2 System operating environment.

(Personal Computers) or mobile devices, as there is no difference in functions on different information terminals, the same function can be used from any device. PCs are assumed to be used indoors for gathering information or evaluating sightseeing spots. On the other hand, mobile devices are assumed to be used both indoors and outdoors to gather information concerning sightseeing spots.

\subsection{System Operation Environment}

The system operates using the web server, database server and the GIS server. Fig. 2 shows the operating environment of the system. The web server and database server both use Heroku, which is a PaaS (Platform as a Service) provided by the Salesforce company. For the GIS server, ArcGIS Online provided by the ESRI (Environmental Systems Research Institute, Inc.) was used. The Web application developed with the system was implemented using PHP (Hypertext Preprocessor) and JavaScript.

\subsection{System Structure}

\subsubsection{SNS}

In the present study, an original SNS, which can be integrated with Twitter, Web-GIS, the recommendation system, was designed. As the purpose of the designed SNS will not only be communication between users but also the gathering of sightseeing spot information, which will serve as the base information for preference information of users as well as recommendations, functions that promote friend registration and community communication was not implemented. The main functions of the designed SNS will be the registration of user information and the submitting, viewing and 
recommending of information. The information made public through profiles will use nicknames instead of real names, and information that may identify an individual, such as gender or age, will not be made public. The comment function and tag function were designed as a method of communication. Comments that are submitted by means of the comment function will also be used as real-time information. Additionally, tags that have been added to sightseeing spots by means of the tag function will be treated as features of the sightseeing spots, and will be used by the recommendation function of sightseeing spots with the preference information of users as the base.

\subsubsection{Web-GIS}

As the present study assumed that the system users will be an unspecified large number from both inside and outside the region of operation, it is better if the system can be used by means of a web browser instead of having users install special software. Additionally, it is necessary to conduct route searches as well as information visualization on digital maps. Therefore, the Web-GIS, which were developed using the ArcGIS API (Application Programming Interface) for JavaScript of the ESRI, is used.

Regarding route searches on 2D digital map, the ArcGIS Online Directions and Routing Services of the ESRI were used. Though Google Maps was the most used in preceding studies of related fields listed in section 2, ArcGIS API for JavaScript is used in the present study. The process up to the display of routes concerning Web-GIS, which used the ArcGIS API for JavaScript and ArcGIS Online Directions and Routing Services as mentioned above, is as shown in Fig. 3. First, the request for a route search as well as search criteria will be sent from ArcGIS for JavaScript API to the ArcGIS Online Directions and Routing Services. Next, after receiving route search results from the ArcGIS Online Directions and Routing Services, the route will be displayed on the Web-GIS developed by means of ArcGIS for JavaScript API.

Regarding route searches on 3D digital map, a
Web-GIS is developed using ArcGIS API for JavaScript of the ESRI. Additionally, for route search, Network analysis services of ArcGIS server is used to derive routes. Because it is necessary to create a $3 \mathrm{D}$ digital map before routing, and necessary data is firstly gathered to create shapefiles using QGIS which is an open source GIS and provided by the GNU (General Public Licenses). Next, 3D layers are created using these shape files and ArcGIS Pro of the ESRI. However, in order to use these 3D layers in ArcGIS online, it is necessary to create a scene layer packages. Therefore, these 3D layers are converted into multi patch feature class to be converted into scene layers package using ArcGIS Pro. Finally, these layers are used as a base, and route search is conducted using ArcGIS API for JavaScript. The process from data gathering up to route display as mentioned above is as shown in Fig. 4.

\subsubsection{Recommendation System}

The recommendation system has 3 methods including the collaborative recommendation, the content-based recommendation and the knowledge-based recommendation [32, 33]. The recommendations of the present study, which is based on the preference information of users concerning the sightseeing support, are conducted using two methods. The first is the knowledge-based recommendation, which recommends sightseeing spots that have features which match the tags registered as preference information by users. The reason for using the knowledge-based recommendation is to solve the cold-start problem, which is when appropriate information to recommend new users to the system is lacking. Therefore, as it was decided that knowledge-based recommendation which explicitly ask users for preference information and create profiles are necessary, the system was originally designed according to the purpose of the present study.

The second is the collaborative recommendation, which supports the tour planning based on the activity 


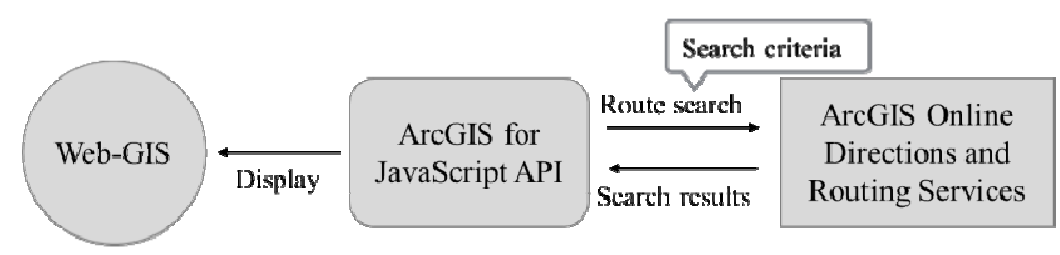

Fig. 3 Process up to the route display on 2D digital map.

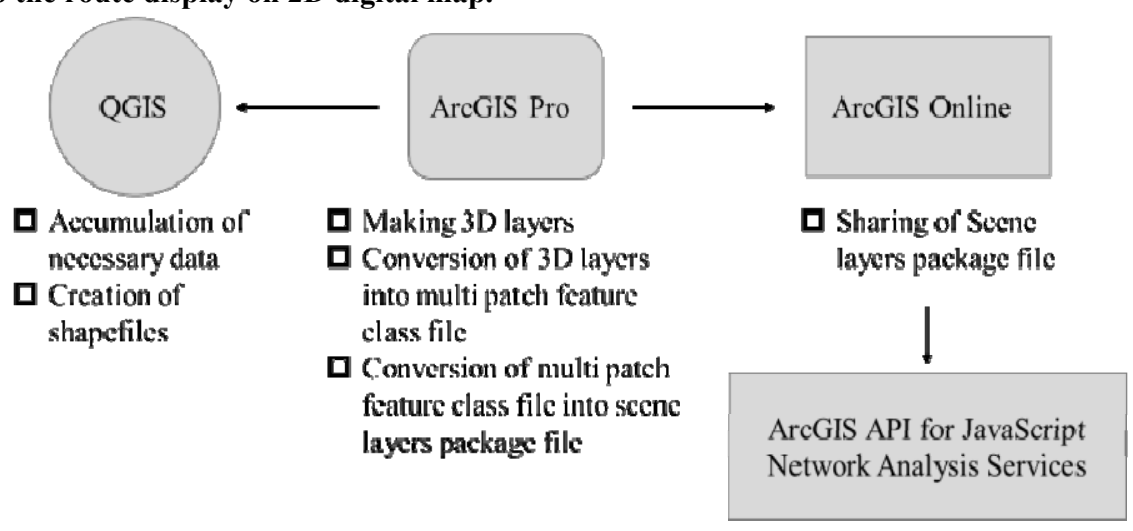

Fig. 4 Process up to the route display on 3D digital map.

history registered by users. Activity history lists sightseeing spots, which were visited in one day, in chronological order, and shows whether users were satisfied or dissatisfied with each sightseeing spot. Based on this information, a user model is created using the SVM (Support Vector Machine), the model is matched with the activity history of other users, the degree of similarity is determined, and users with similar preferences are detected.

Afterwards, regarding the activity history of users with similar preferences, a pattern mining, which lists and extracts time series activities of sightseeing a group of locations, will be conducted. The pattern mining in the present study uses categories. The seven categories, which divide sightseeing spots according to each feature, used in the present study include food and drinks, shops, entertainment, event, landscape, art and recreation, and others. All sightseeing spot information belongs to one of these categories. Therefore, each sightseeing spot's information in the activity history will be put in the category it belongs to, and the categories corresponding to the list of sightseeing spots visited in chronological order will be used as the new activity history. Then, the system will extract patterns of categories from the activity history of users with similar preferences, and recommend patterns with the highest relativity score as described in section 5. Regarding each category within the recommended patterns, by selecting and matching sightseeing spot information belonging to each category, a tour plan is made.

\subsubsection{Management of Submitted Information}

As the standard of validity of submitted information concerning sightseeing spots is vague, it is difficult to determine whether or not the content is appropriate. However, if information submitted by users is not managed, when a user with ill intent appears, the reputation of a specific sightseeing spot may be damaged arbitrarily. If users have knowledge concerning the region of operation, the legitimacy of submitted information can be determined based on experience. However, users who do not have any knowledge will not be able to determine the legitimacy and may make incorrect evaluation concerning sightseeing spots. In this case, the information of the sightseeing spot is inappropriate, and it will affect information recommendations as recommendations suitable for users will not be possible, which will ultimately damage the value of the system. Therefore, in the present study, if the 
manager detects any submissions with ill intent, regarding the account that created the submission with ill intent, the system is designed so that authority to delete the submission and account can be exercised. By means of this, the present study aims to design a system that can operate on a long-term basis.

\section{System Development}

\subsection{The Frontend of the System}

The system will implement unique functions for users, which will be mentioned below, in response to the aim of the present study, as mention in section 1 . In order to implement these several unique functions, the system was developed by integrating plural systems into a single system, and is also connected with external SNS.

4.1.1 Submitting Function of Sightseeing Spot Information

By clicking on the "Submit a spot" in the menu bar, users will be moved to the submitting page of sightseeing spot information. Fig. 5 shows the page for the submitting function of sightseeing spot information. On this page, users can submit sightseeing spot information by entering the name, description, images and location information of the sightseeing spot. The location information of the sightseeing spot can be entered by clicking the target location on the Web-GIS. Additionally, by clicking the "display past submitted locations", users can confirm whether the same sightseeing spot information has been submitted in the past.

4.1.2 Viewing Function of Sightseeing Spot Information

Users can return to the homepage by clicking "home" in the menu bar, and view sightseeing spot information submitted by users in the past on the Web-GIS. Fig. 6 shows the pages for the viewing function of sightseeing spot information. Each sightseeing spot's information is displayed with different color markers according to each category, and the category of each marker is explained in the image below the Web-GIS. When clicking the marker, a bubble containing the name and image of the sightseeing spot will be displayed. By clicking the bubble, users will be moved to the details page of the selected spot which will enable them to check the detailed information.

In the details page of sightseeing spots, the comment and tag functions can be used. The comment function will enable communication between users as well as supplementary information to be added to sightseeing spot information. Additionally, Tweets related to sightseeing spots obtained through Twitter is also displayed in the comment section. These comments and Tweets are considered real time information of sightseeing spots. Regarding the tag function, the features of sightseeing spots can be freely added as tags by users. Users can use tags that

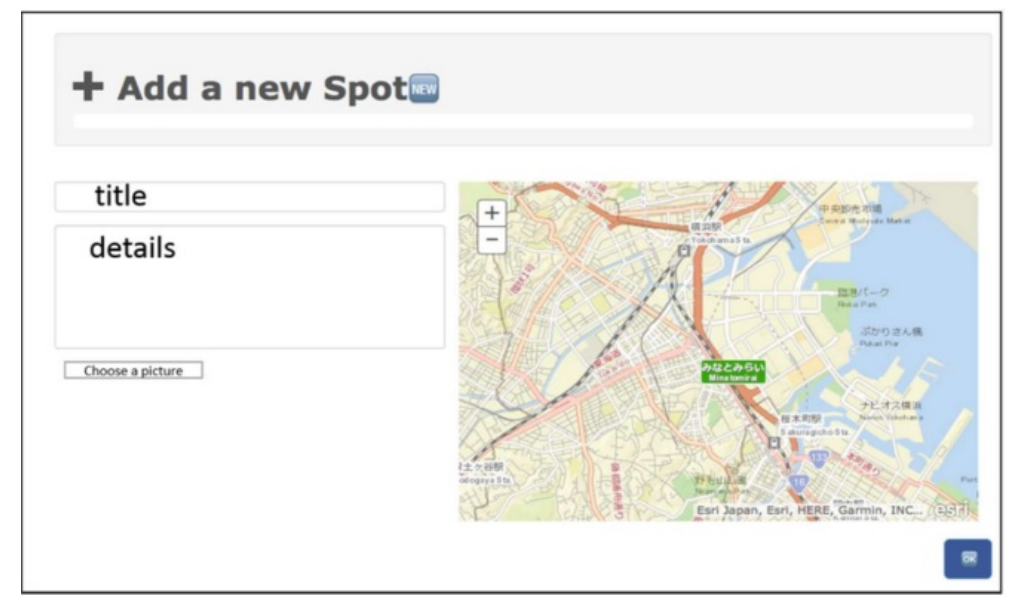

Fig. 5 Page for the submitting function of sightseeing spot information. 


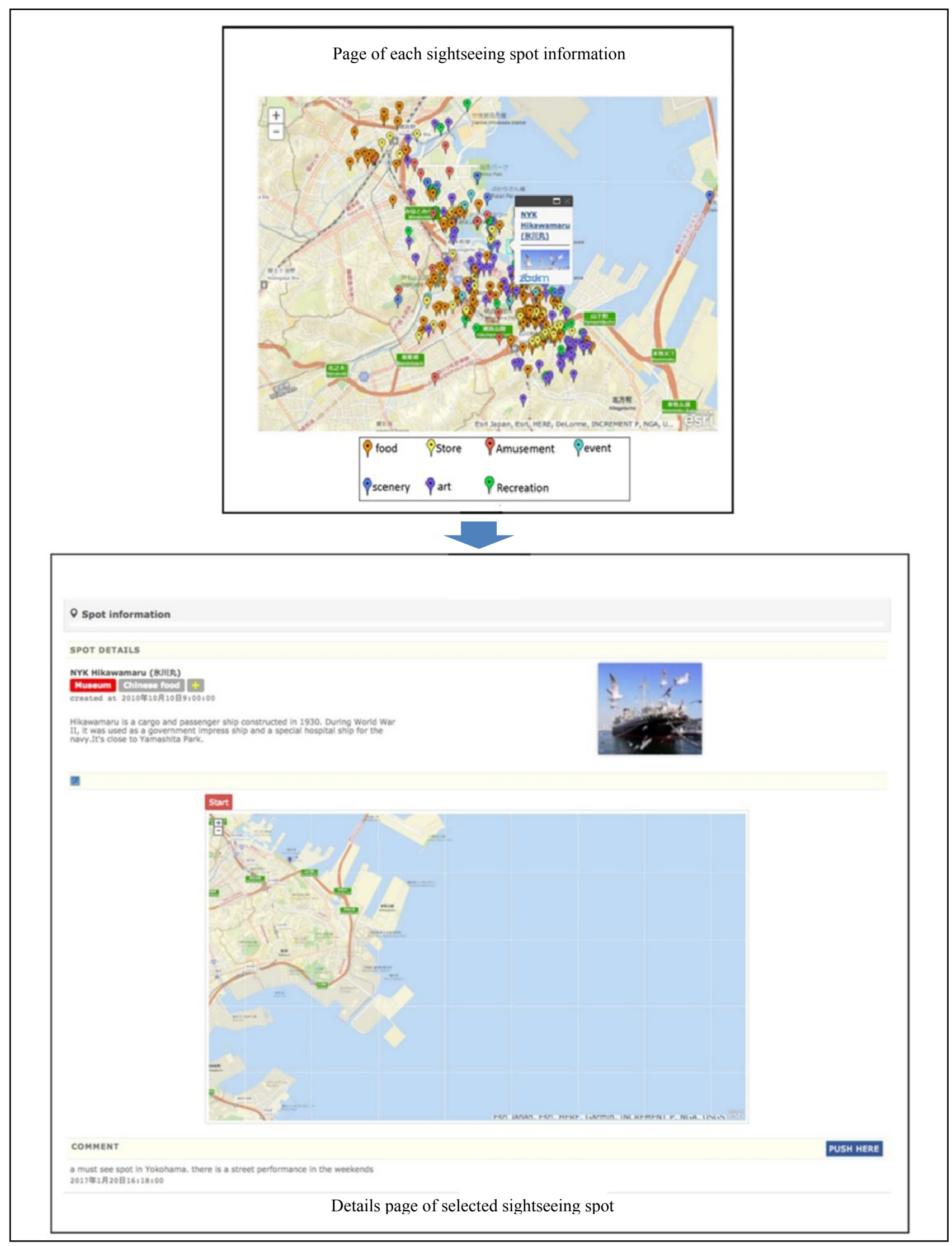

Fig. 6 Pages for the viewing function of sightseeing spotinformation. 


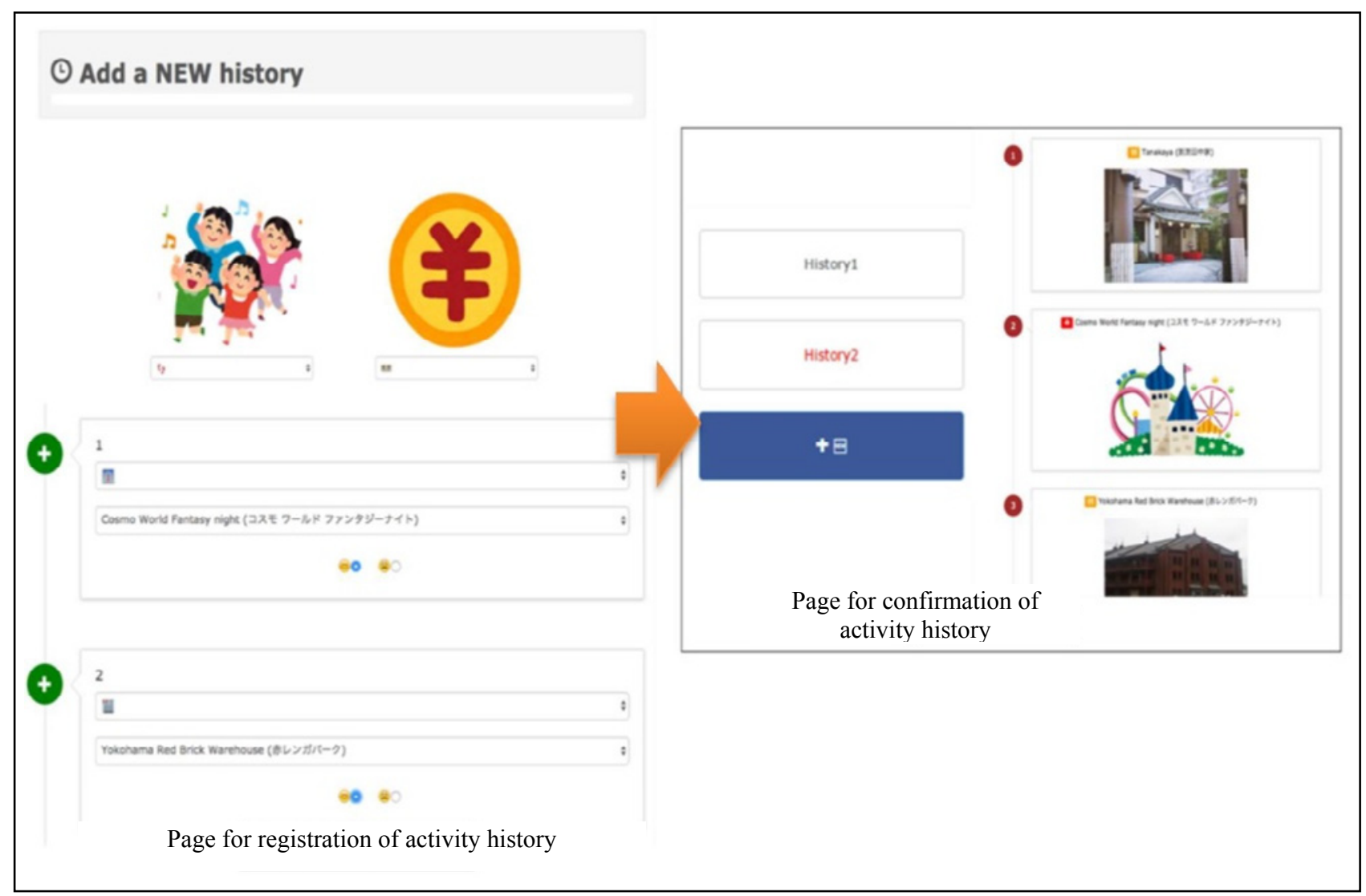

Fig. 7 Pages for the registering function of activity history.

have been registered in the past as well as tags that have been newly registered. Moreover, by clicking tags that have already been added, additional importance can be placed on the tag. The most commonly used tag will be used as the feature of the sightseeing spot when recommended. All tags belong to a category, and the category that the most-used tag of a sightseeing spot belongs to will also be the category in which the sightseeing spot belongs to. Furthermore, by clicking on "start navigation from your current location", users can receive navigation on the Web-GIS to any sightseeing spot from their current location.

\subsubsection{Registering Function of Activity History}

By clicking on "history" in the menu bar, users will be moved to the pages of registering function of activity history shown in Fig. 7. Activity history is made up of users' evaluation of previously visited sightseeing spots, within the region of operation, in addition to the budget and group when visiting the sightseeing spots. The numbers of sightseeing spots that can be registered are 2 to 5 . Additionally, if the activity history is already registered, the confirmation screen of activity history will appear. On the confirmation screen of activity history, by clicking the button with each activity history name, users can confirm the activity history registered in the past. The contents of activity history that will be displayed include the name, image and category of each sightseeing spot.

\subsubsection{Support Function of Tour Planning}

Fig. 8 shows the pages for the support function of tour planning. By clicking "plans" in the menu bar, users will be moved to the page for the support function of tour planning. Regarding this page, users can receive tour planning support from the system based on the registered activity history. First, regarding the tour planning, the budget and group and the number of sightseeing spots that the users would like to visit must be entered and sent as conditions. 


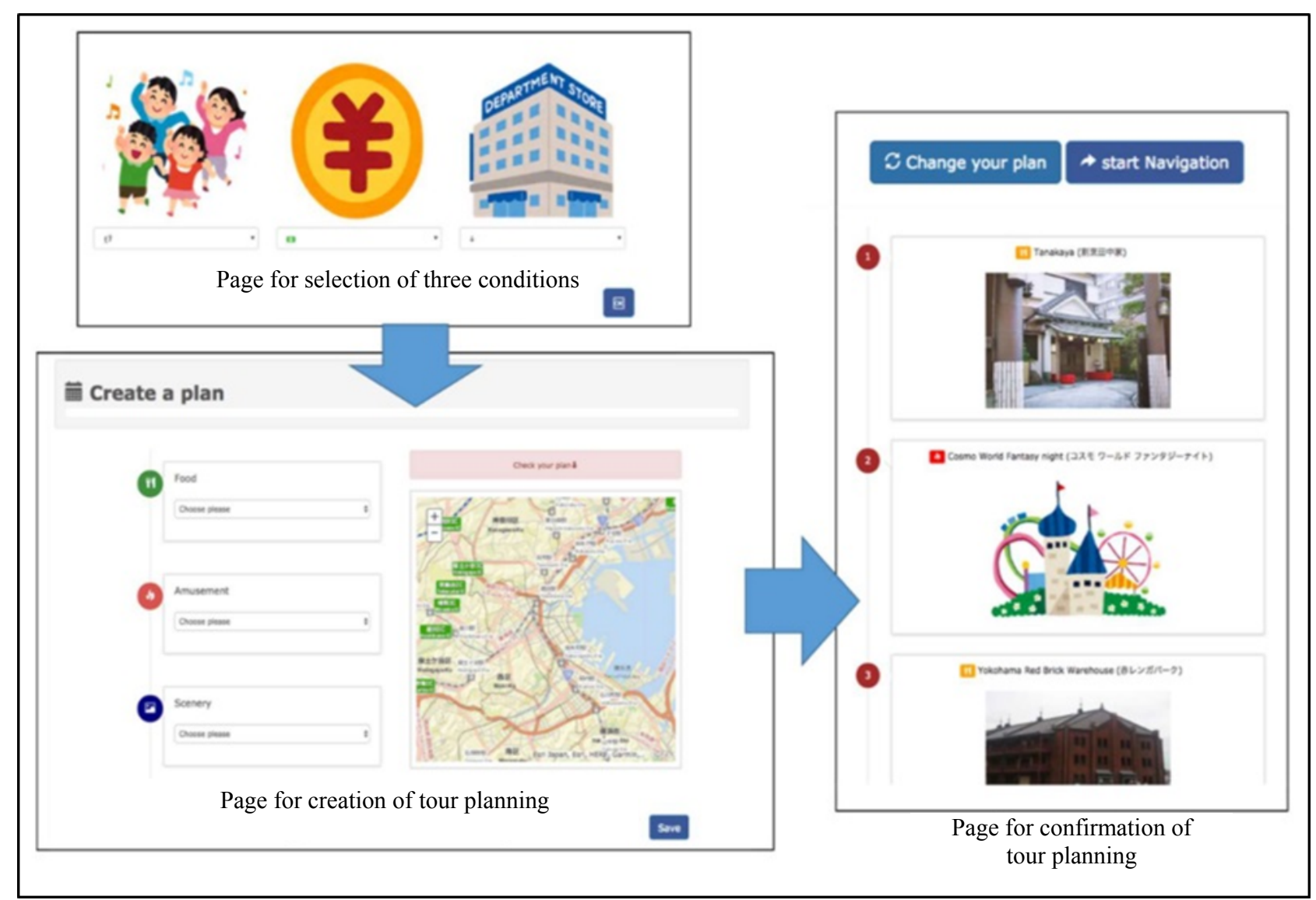

Fig. 8 Pages for the support function of tour planning.

Based on the conditions and activity history of each user, the system will recommend patterns made up by categories. Regarding each category in the pattern recommended, users can select and match sightseeing spots belonging to each category and create a tour plan. Additionally, in order to efficiently create a tour plan, the location information of sightseeing spots applied to each category will be actively displayed on the Web-GIS. If the tour plan is already made, users will be moved to the tour plan confirmation screen, and the name, image and category of sightseeing spots will be displayed according to the order on the sightseeing schedule.

\subsubsection{Navigation Function}

The system conducts navigation on $2 \mathrm{D}$ and $3 \mathrm{D}$ digital maps of the Web-GIS is shown in Fig. 9. More specifically, Fig. 9 shows the three pages for navigation of single sightseeing spots on 2D digital map, several sightseeing spots on 2D digital map, and several sightseeing spots on 3D digital map. Regarding 2D digital map, by clicking the "start 2D navigation from current location" on the details page of sightseeing information or the "start navigation" on the page for confirmation of the tour plan, as shown in Fig. 9, the first option will take the users to the page for navigation function for single sightseeing spots, and the second will take users to the page for navigation function for several sightseeing spots. Regarding navigation for single sightseeing spots, navigation will be conducted by displaying the current location shown in red and the route from the current location to the user's destination shown in purple on 2D digital map. Additionally, for navigation of several sightseeing spots, the navigation will be conducted by simultaneously displaying the current location shown in red and the route for several sightseeing spots shown in purple. 

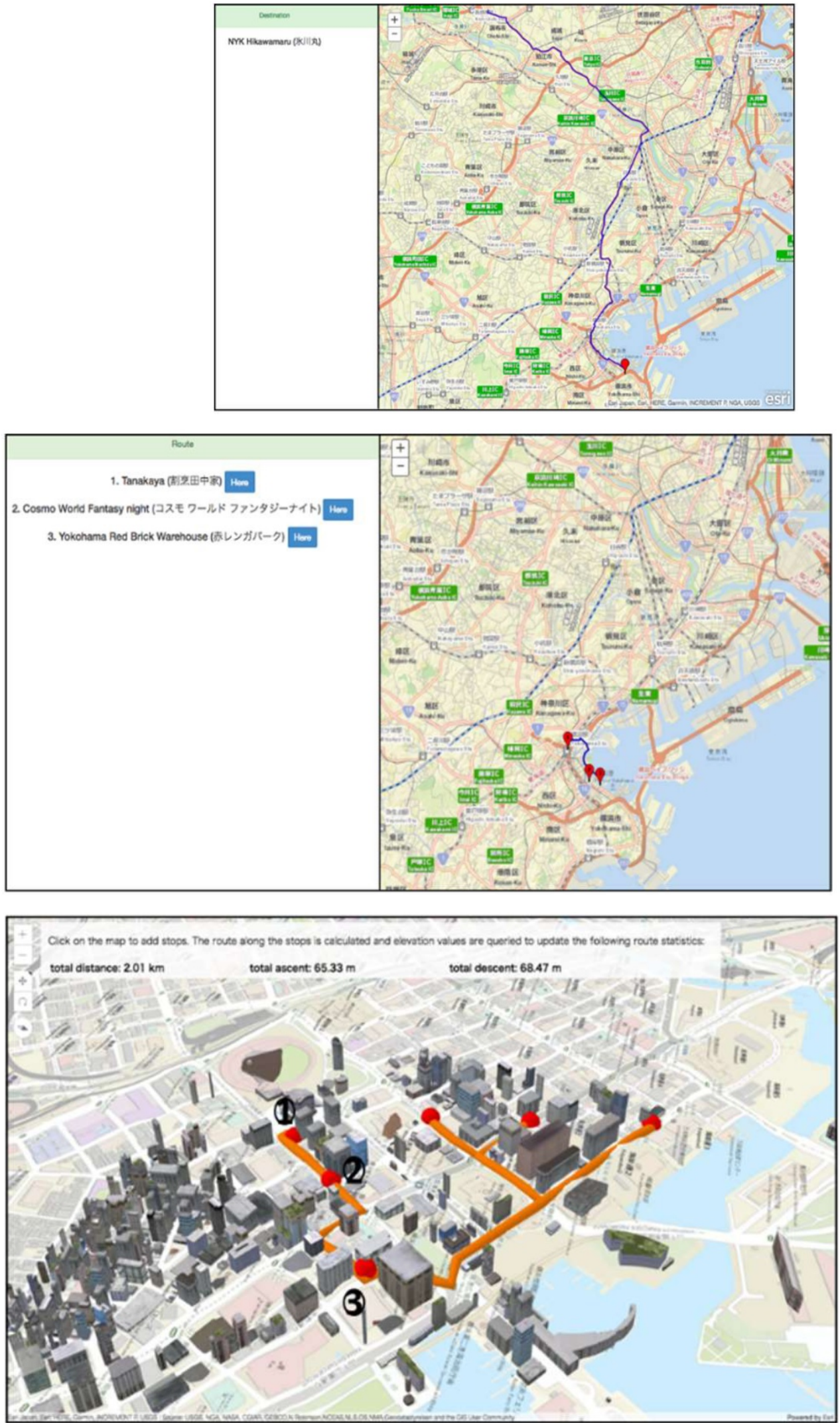

Fig. 9 Three pages for navigation of single sightseeing spot on 2D digital map, several sightseeing spots on 2D digital map, and several sightseeing spots on 3D digital map. 


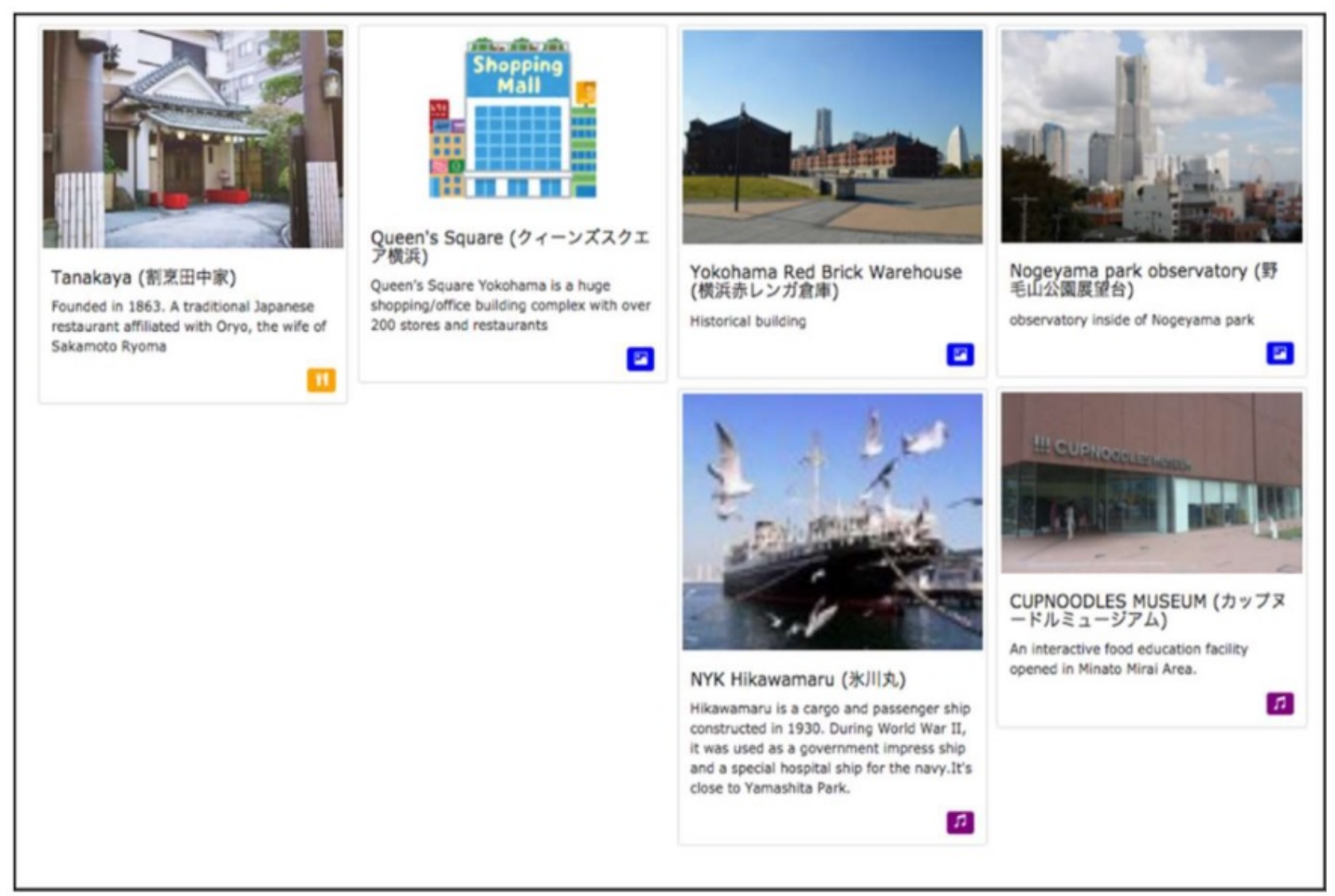

Fig. 10 Pages for the recommendation function of sightseeing spot.

Regarding 3D digital map, by clicking the "start 3D navigation from current location" on the home page, users will move to the page for 3D digital map. On this page, by clicking the buildings displayed in $3 \mathrm{D}$ digital map, users can confirm the sightseeing spot information including name, explanation and pictures. When users select the current location and their destinations which are shown in red, the route between these points will be displayed in orange. Additionally, on this page, users can also know the distance between these points.

\subsubsection{Recommendation Function of Sightseeing} Spot

As shown in Fig. 10, users will be moved to the page for the recommendation function of sightseeing spot by clicking the "recommended" in the menu bar, and sightseeing spots with the most-used tags that are also registered as the users' preference information will be recommended. The information of the recommended sightseeing spots will be listed in tile form, and the content will include the name, description, image and category of each sightseeing spot.

\subsection{The Backend of the System}

4.2.1 Calculation of the Similarity Ratio of Preferences between Users

With the method of Fujitsuka, T., et al. [5] as a reference, SVM will be used for the similarity rate calculations of preferences between users in the present study. SVM is one of the methods of machine learning, and it can also make models that discern different patterns in order to divide data into several classes. In the present study, users' activity history will be used as learning data, and budget/group and tags will be treated as features, while class will be divided into satisfactory class and dissatisfactory class. First, a user model based on the activity history of 
users will be made, the activity history of a different user will be applied to it, and the data will be divided into the satisfactory class or the dissatisfactory class. By comparing the aforementioned user model and the separation results, the ratio of matched satisfaction and dissatisfaction among the activity history will be set as the preference similarity rate between users. Using the study results of Fujitsuka, T., et al. [5] and Fujita, S. and Yamamoto, K. [8] as a reference, and basing the level of similarity rates discerned as being able to appropriately determine similar users by the operation tests (section 6) mentioned later, the present study will set those with a similarity rate of over $60.0 \%$ as users with similar preferences.

\subsubsection{Making Recommendations}

The system will make recommendations for users in order to support the sightseeing spot recommendation based on their preference information as well as the tour planning based on their activity history. Regarding the former, tags registered as users' preference information and the most-used tags included in sightseeing spot information will be put together, and the matching sightseeing spot information will be recommended. Regarding the latter, calculations of the preference similarity rate between users will be made, and based on the activity history of users with similar preferences as well as their conditions, recommendation will be made using the pattern mining method. In particular, sightseeing spot information included in the activity history will first be converted to the category it belongs to, and the category group will be made. Then, all patterns from the category groups will be extracted. Next, as shown in Fig. 11, the closeness (degree of distance) will be solved for the extracted patterns considering the chronological order of the categories, and the closeness score of each pattern will be calculated by multiplying the support rate of patterns (appearance ratio). The pattern with the highest closeness score will be recommended to users.

\subsection{The Interface of the System}

The interface is optimized according to the user's PC screens (Fig. 12), mobile information terminal screens and manager screens. The PC screen interface has the layout with a menu bar allowing easy access to each function. Additionally, because it is designed to use 1 function on 1 page, users who are new to the system can easily use it. The interface for mobile information terminals is basically the same as PCs, but by changing the layout and size of items according to the size of the screen, the operability of the system is made easy. Managers can manage information saved in the database, which include personal information of users' and submitted information, on the manager screen. Information is displayed in a list form on the manager's screen, and as information is deleted using

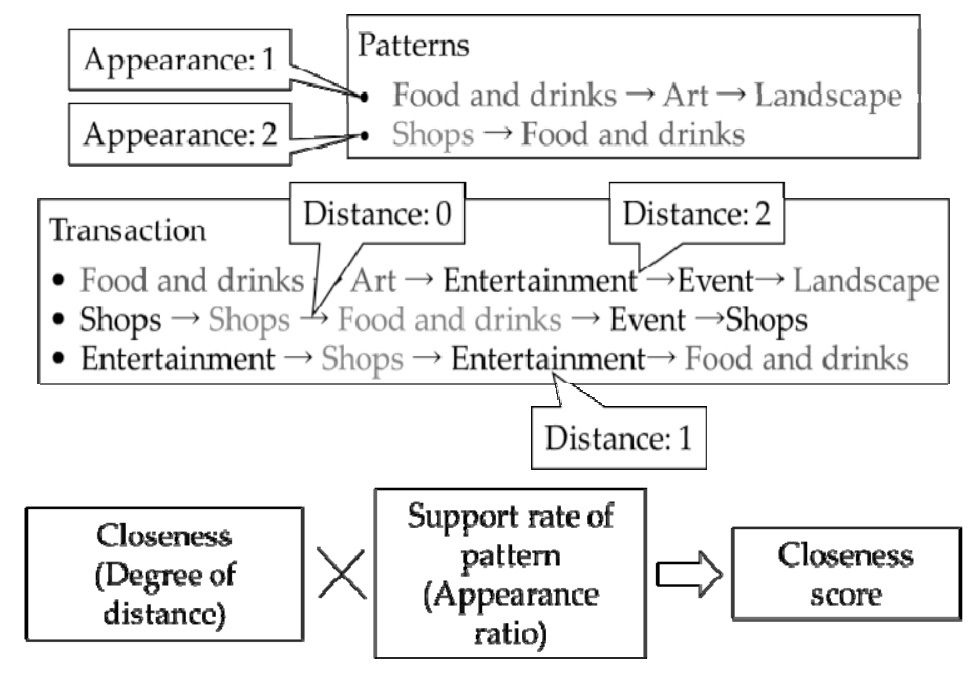

Fig. 11 Calculation method of closeness score. 


\section{AHome @Your history E}
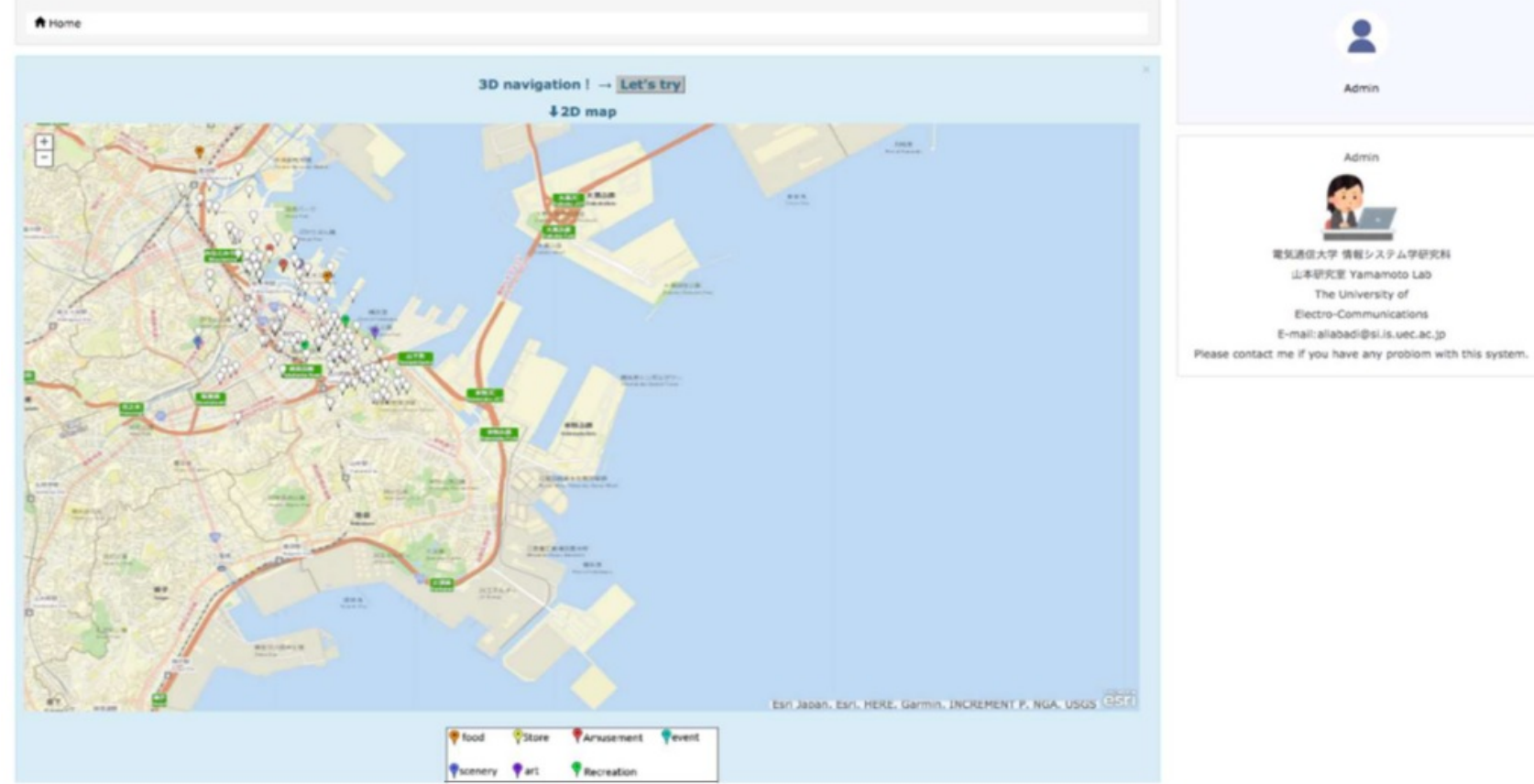

Fig. 12 Interface for PCs.

the GUI (Graphical User Interface) operation, the system is designed so that management can be possible regardless of the manager's IT literacy.

\section{Operation}

\subsection{Sightseeing Spot Data}

In order to enable the use of functions right after the operation starts, it is necessary to gather sightseeing spot information beforehand. Therefore, 180 sightseeing spot information items in the social recommendation GIS developed by Ikeda, T. and Yamamoto, K. [30] were gathered, edited by referring to the travel review site, 4travel.jp. [34], and accumulated in the system in advance. All of the names of sightseeing spots and submitted information are translated from Japanese to English.

Additionally, when using the recommendation function of sightseeing spots, evaluation values concerning each sightseeing spot are needed. Therefore, the evaluation values were updated by referring to the aforementioned 4travel.jp [34]. When doing so, the number of evaluators in the same website is recorded according to each sightseeing spot. This is used as a parameter for the recalculation of new evaluation values when a user evaluated a sightseeing spot. However, if the number of evaluators is extremely low, the evaluation values obtained from the aforementioned preceding study are used, and the evaluators are each counted as one person. Referring to Ikeda, T., Yamamoto, K., Fujita, S. and Zhou, J. [8, $14,30]$, the system categorized all sightseeing spots into seven categories including "food and drinks", "shops", “entertainment”, “event”, "landscape”, “art and recreation" and "others".

\subsection{User Assumption}

Those who are planning a trip within the operation target area, those who have visited the operation target area, as well as those living within the operation target area, are assumed users of the system. Additionally, the assumed users of the system should be just foreigners. Regarding those planning a sightseeing trip within the operation target area, it is assumed that they will gather information concerning sightseeing spots 
they are interested in by using the recommendation function of sightseeing spots, and obtain detailed sightseeing spot information by means of the viewing function of sightseeing spot information. Regarding those who have visited or are living within the operation target area, they are encouraged to evaluate the sightseeing spots they have visited. Additionally, it is expected that such users will also utilize the viewing function of sightseeing spot information and recommendation function of sightseeing spots to obtain the information concerning new places they have never visited before.

\subsection{Operation}

\subsubsection{Operation Overview}

The operation of the system was conducted for a week with those inside and outside the operation target area. Whether inside or outside the operation target area, the operation of the system was advertised using the website of the author's lab as well as Twitter and FaceBook. Additionally, the tourism department of Kanagawa Prefecture and Yokohama city in addition to the Yokohama Convention and Visitors Bureau (Yokohama City Tourism Association) supported the present study by distributing pamphlets and operating manuals.

Users register when using the system for the first time. User registration can be done either by registering an ID and password, or by logging in to external SNS. For both methods excluding the use of FaceBook, preferences are also registered in addition to "gender" and "age". If users register with FaceBook, information concerning "gender" and "age", which is registered with FaceBook, will be received and registered. After completing the registration, users will automatically go to the top page, and the use of functions within the system will be made available. Group registration will be also available from "my page", and this will enable the use of the recommendation function of sightseeing spots as a group. Moreover, it made possible to change user information as well as preferences through "my page", and this will allow users to receive sightseeing spot recommendations that meet their preferences.

5.3.2 Management of Submitted Information by Administrators during the Operation

Every user's submissions of information and image files are all accumulated as data in the database of the system. Administrators manage users and check submitted information using a list screen designed especially for the purpose. Administrators can take the measure of suspending accounts of users who have made inappropriate transmissions or behaved inappropriately, and if by any chance an inappropriate submission is made, administrators can delete the submission with just one click. Due to these features, there is no need for administrators to search to see whether or not inappropriate submissions of information have been made within the system; therefore, their burden can be lessened.

\subsubsection{Operation Results}

\subsubsection{Characteristics of Users}

Users of the system are shown in Table 1. The system has a total of 52 users with 32 male and 20 female users. Regarding age groups, there are many male and female users in their 20s making up $52 \%$ of the total. Subsequently, those in their 40 s were $28 \%$, those in their 10 s were $9 \%$ and those in their 40 s were $5 \%$. Fig. 13 shows users' nationalities. As shown in Fig. 13, the users contain the people whose native languages are not English. After having each user use the system for a week, the evaluation by means of a web questionnaire survey was conducted.

5.3.3.2 Submission of Sightseeing Spot Information and Use of the Comment Function and Tag Function

During the operation period, no sightseeing spot information was submitted. Because the information concerning popular sightseeing spots was already accumulated in the system, and the system could provide enough sightseeing spot information to foreign users. Additionally, since all users are foreigners, and they did not know sightseeing spots, it 
Table 1 Outilne of users and respondents to the web questionnaire.

\begin{tabular}{llllllll}
\hline Age groups of users & $10-19$ & $20-29$ & $30-39$ & $40-49$ & $50-59$ & $60-$ & Total \\
\hline Number of users & 5 & 28 & 15 & 3 & 2 & 1 & 54 \\
Number of web questionnaire survey respondents & 0 & 23 & 11 & 2 & 1 & 1 & 38 \\
Valid response rate (\%) & 0.0 & 82.1 & 73.3 & 66.6 & 50.0 & 100.0 & 70.3 \\
\hline
\end{tabular}

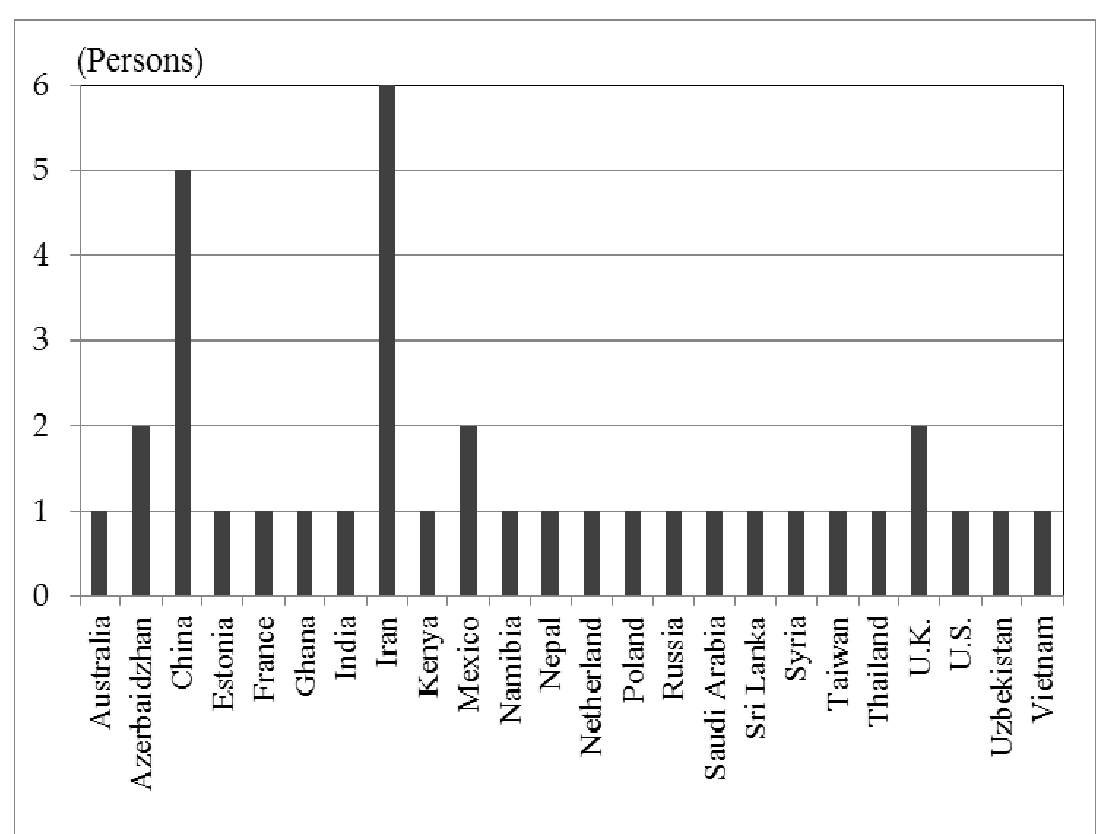

Fig. 13 Users' nationalities.

was impossible for them to submit sightseeing spot information during the operation period.

Ten comments were made and 18 tags were registered to sightseeing spot information, 35 times of additional importance was placed on the tag by users during the operation period. Though the comment function is not often used, and evaluation using the tag functions was often made, it is understood that users communicated each other mainly through the tag functions. This may because the tag function is easier to use as users only need click on a tag to give the submission more weight, while the comment function requires users to enter sentences.

\section{Evaluation}

After the end of the operation, a web questionnaire survey and access analysis of users' log data were conducted in order to evaluate the system developed in the present study.

\subsection{Evaluation Based on Web Questionnaire Survey}

\subsubsection{Overview of the Web Questionnaire Survey}

Along with the purpose of the present study, a web questionnaire survey was implemented in order to conduct (1) evaluation concerning the use of the system and (2) evaluation concerning the functions of the system. The web questionnaire survey was conducted for 1 week after the start of the operation. Table 1 also shows an overview of the web questionnaire survey. As shown in Table 1, 32 out of 52 users submitted their web questionnaire survey, and the valid response rate was $70 \%$.

6.1.2 Evaluation Concerning the Use of the System

6.1.2.1 Evaluation of Suitability with the Information Acquisition Method for Sightseeing Spots

Regarding information acquisition methods for sightseeing spots (multiple answers allowed), 38\% were PCs, $59 \%$ were mobile devices and $3 \%$ were others (guidebooks, pamphlets and flyers). Therefore, 
it was made evident that many users obtain sightseeing information from the Internet using PCs and mobile devices in addition to using printed mediums such as guidebooks, pamphlets and flyers. Regarding the devices which were used to success to the system, 45\% were PCs and $55 \%$ were smartphones. Therefore, users accessed the system equally using PCs and smartphones. These also made it clear that the system, which obtains sightseeing spot information using PCs and mobile devices, is effective.

6.1.2.2 Evaluation for Each Specific Function as well as the Whole System

The evaluation results for each specific function and the entire system are shown in Fig. 14. Regarding the suitability of sightseeing spots recommended, all users answered "suitable" or "somewhat suitable", and the former was highly $58 \%$. Regarding the usefulness of 3D digital map, $82 \%$ answered "useful" or "somewhat useful", and 18\% answered "not so useful". From this point, it is sufficient for some users to use just 2D digital map, not using 3D digital map.

Regarding the suitability of display of sightseeing spot information, $87 \%$ answered "suitable" or "somewhat suitable", and 13\% answered "not so suitable”. In order to support foreigners' sightseeing behaviors, principal language is English and real pictures are adapted as many as possible in the system. Moreover, signs, marks and pictograms are adapted in the case that the real pictures of sightseeing spots were not acquired. However, it was evident that some users thought the display of sightseeing spot information in the system was not so serviceable.

Regarding the usefulness of the system when sightseeing, all users answered "I think so" or "I somewhat think so". Because the system is highly useful when sightseeing as indicated by the results above, it can be expected that users will more fully use each function by continuously operating the system.

\subsection{Evaluation Based on Access Analysis}

\subsubsection{Access Analysis Method of Users' Log Data}

In the present study, an access analysis was conducted using the users' log data during the operation period. This analysis was conducted using Google Analytics which is a Web access analysis service provided by Google. A PHP program with the analysis code made using Google Analytics was created, and for the target websites for the access

Suitability of sightseeing spots recommended

Usefulness of 3D digital map

Suitablity of display of sightseeing spot information

Usefulness of the systemin the present study

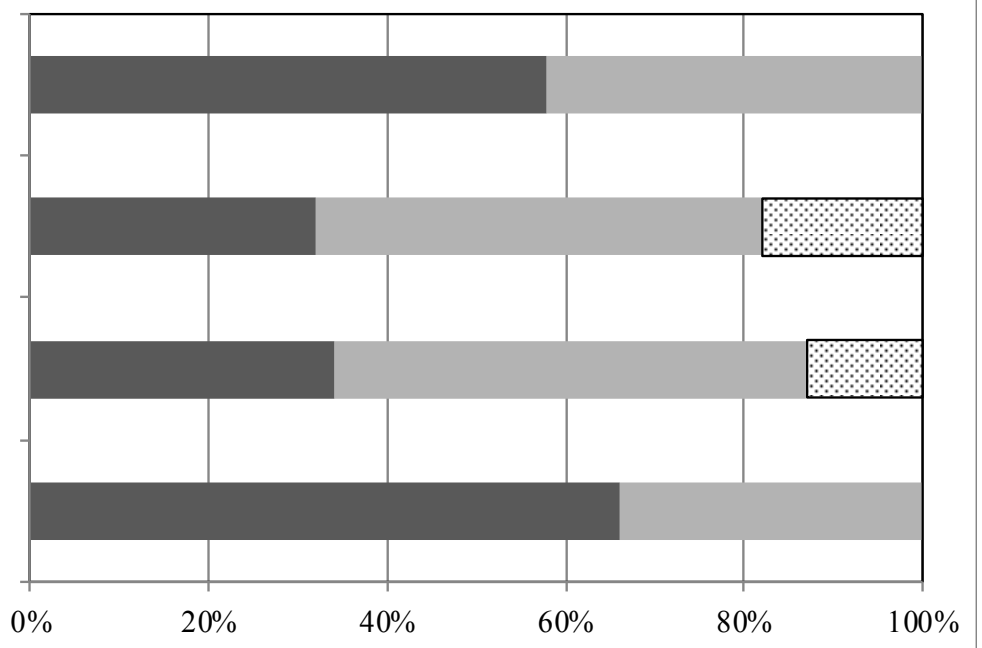

- Suitable/Useful

Somewhat suitable/Somewhat useful

Đot so suitable/Not so useful

- Not suitable/Not useful

Fig. 14 Evaluation results for each specific function and the entire system. 
Table 2 Access methods.

\begin{tabular}{lll}
\hline Access method & Number of sessions & Percentage (\%) \\
\hline PCs & 49 & 65.3 \\
Mobile information terminals & 26 & 34.7 \\
\hline
\end{tabular}

Table 3 Number of visits according to papg (Top 10).

\begin{tabular}{llll}
\hline Rank & Page name & Number of page visits & Percentage (\%) \\
\hline 1 & Viewing function of sightseeing spot information & 192 & 26.4 \\
2 & Registering function of activity history & 153 & 20.9 \\
3 & Support function of tour planning & 104 & 14.3 \\
4 & Navigation function on 3D digital map & 92 & 12.7 \\
5 & Navigation function on 2D digital map & 75 & 10.2 \\
6 & Recommendation function of sightseeing spot & 68 & 9.3 \\
7 & Submitting function of sightseeing spot information & 46 & 6.3 \\
\hline
\end{tabular}

analysis, the access log was obtained by scanning the PHP program made for the access analysis of the program in each page within that website.

\subsubsection{The Results of Access Analysis}

The access method to the system is shown in Table 2. As shown in Table 2, there is a clear difference in the use of PCs and mobile information terminals as an access method. More specifically, it is evident that PCs were more used rather than mobile information terminals. This is because the system conducted navigation on 2D and 3D digital maps of the Web-GIS. The number of visits according to page is shown in Table 3. As it is made clear in Table 3, the page for viewing function of sightseeing spot information have the most visits. Additionally, the rate of the page for registering function of activity history is $20.9 \%$, the page for support function of tour planning is $14.3 \%$, the page for navigation function on 3D digital map is $12.7 \%$, and the page for navigation function on $2 \mathrm{D}$ digital map is $10.2 \%$. From these results, it can be said that the system was mainly used before sightseeing. Moreover, users confirm their favorite sightseeing spots and made their tour planning in advance, using $2 \mathrm{D}$ and $3 \mathrm{D}$ digital maps.

\subsection{Extraction of Improvement Measures}

The issues concerning the system were extracted based on the results of the web questionnaire survey, as well as the access analysis of users' log data, and they are summarized below:

(1) Non-language information on the all pages

Since all of the foreign tourists are not so good at English, it is necessary to decrease the letters and increase non-language information in an easy-to-understand manner even more than now on the all pages of the systems. Thus, the system can respond to more foreign tourists from various countries.

(2) Sightseeing spot information on 3D digital map

The system conducted navigation using 3D digital map in addition to 2D digital map of the Web-GIS. However, on 3D digital map, because it is slightly difficult to select a point, it is necessary to display the sightseeing spot information by creating popup windows.

\section{Conclusion}

The conclusion of the present study can be summarized into three points as shown below:

(1) In order to support foreign tourists' efficient acquisition of sightseeing spot information in Japanese urban tourist areas, by integrating a Web-GIS, an SNS and a recommendation system, a sightseeing navigation system that can display location information and routes was designed and developed. It was possible to use the non-language information such as signs, marks and pictograms in addition to English information, and display 
sightseeing spot information and conduct navigation using $2 \mathrm{D}$ and $3 \mathrm{D}$ digital maps of the Web-GIS. The central part of Yokohama city in Kanagawa Prefecture, Japan, was chosen as the operation target area, and operation and evaluation of the system were conducted.

(2) The operation of the system was conducted for two weeks just targeting foreigners, and a web questionnaire survey was conducted towards all users. Among the 54 users, a total of $52 \%$ were in their $20 \mathrm{~s}$, and their nationalities are various. Based on the results of the web questionnaire survey, all of the specific functions are highly evaluated, and the usefulness of the system when sightseeing was excellent. However, it also shows the necessities to improve the display of non-language information on the all pages and sightseeing spot information on 3D digital map of the Web-GIS.

(3) From the results of the access analysis of users' $\log$ data, it is evident that it can be said that the system was mainly used before sightseeing and users confirm their favorite sightseeing spots and made their tour planning in advance, using 2D and 3D digital maps. Therefore, in the next step of the present study, it is necessary to inspect this point by the even more long-term operation of the system.

As future study projects, the improvement of the system based on the results in section VI-C, as well as the enhancement of the significance of using the system by gaining more results in other urban sightseeing areas can be raised. Furthermore, based on the improved system in the present study, the authors have a plan to commercialize it in cooperation with private companies in the related fields.

\section{Acknowledgment}

In the operation of the dynamic real-time navigation system and the web questionnaires of this study, enormous cooperation was received from those mainly in the Kanto region such as Kanagawa Prefecture and Tokyo Metropolis. The author would like to take this opportunity to gratefully acknowledge them.

\section{References}

[1] Ishizuka, J., Suzuki, Y., and Kawagoe, K. 2007. "Method for Searching for Similarities in Data on Movement Paths, Designed to Support Sightseeing in Kyoto." The Special Interest Group Technical Reports of Information Processing Society of Japan, CVIM, "Computer Vision and Image Media” 2007 (1): 17-23.

[2] Kurata, Y. 2012. "Introducing a Hot-Start Mechanism to a Web-Based Tour Planner CT-Planner and Increasing its Coverage Areas." Papers and Proceedings of the Geographic Information Systems Association of Japan 21: 4.

[3] Kawamura, H. 2012. "Efforts to Spread Standard Tags in Hokkaido Tourist Information, and the Development of Kyun-Channel." Journal of Digital Practice 3 (4): 272-80.

[4] Sasaki, J., Uetake, T., Horikawa, M., and Sugawara, M. 2013. "Development of Personal Sightseeing Support System during Long-Term Stay." In Proceedings of 75th National Convention of IPSJ, 727-8.

[5] Fujitsuka, T., Harada, T., Sato, H., and Takadama, K. 2014. "Recommendation System for Sightseeing Plan Using Pattern Mining to Evaluate Time Series Action." In Proceedings of the Annual Conference on Society of Instrument and Control Engineering, 802-7.

[6] Ueda, T., Ooka, R., Kumano, K., Tarumi, H., Hayashi, T., and Yaegashi, M. 2015. "Sightseeing Support System to Support Generation/Sharing of Sightseeing Information." The Special Interest Group Technical Reports of IPSJ: Information system and Social Environment (IS) 4: 1-7.

[7] Okuzono, M., Muta, M., Hirano, H., Masuko, S., and Hoshino, J. 2015. "Recommendation System of Sightseeing Area for Groups." The Special Interest Group Technical Reports of IPSJ: Human Computer Interaction (HCI) 19:1-8.

[8] Fujita, S., and Yamamoto, K. 2016. "Development of Dynamic Real-Time Navigation System." International Journal of Advanced Computer Science and Applications 7 (11): 116-30.

[9] Kurashima, T., Iwata,T., Irie, G., and Fujimura, K. 2010. "Travel Route Recommendation Using Geotags on Photo Sharing Service." Technical Report of the Institute of Electronics, Information and Communication Engineers, LOIS, "Life Intelligence and Office Information Systems" 109 (450): 55-60.

[10] Van Canneyt, S., Schockaert, S., Van Laere, O., and Dhoedt, B. 2012. "Time-Dependent Recommendation of Tourist Attractions Using Flickr." In Proceedings of the 
23rd Benelux Conference on Artificial Intelligence, 255-62.

[11] Batet, M., Moreno, A., Sánchez, D., Isern, D., and Valls, A. 2012. "Tourist @: Agent-Based Personalized Recommendation of Tourist Activities." Expert Systems with Applications 39 (8): 7319-29.

[12] Uehara, H., Shimada, K., and Endo, T. 2012. "Sightseeing Location Recommendation Using Tourism Information on the Web." Technical Report of The Institute of Electronics, Information and Communication Engineers, NLC, "Natural language Understanding and Models of Communication” 112 (367): 13-8.

[13] Shaw, B., Shea, J., Sinha, S., and Hogue, A. 2012. "Learning to Rank for Spatiotemporal Search." In Proceedings of the Sixth ACM International Conference on Web Search and Data Mining, 717-26.

[14] Zhou, J., and Yamamoto, K. 2016. "Development of the System to Support Tourists' Excursion Behavior Using Augmented Reality.” International Journal of Advanced Computer Science and Applications 7 (7): 197-209.

[15] Yu, C. C., and Chang, H. P. 2009. "Personalized Location-Based Recommendation Services for Tour Planning in Mobile Tourism Applications." In Proceedings of the 10th International Conference on E-Commerce and Web Technologies, 38-49.

[16] Noguera, J. M., Barranco, M. J., Segura, R. J., and Martinez, L. 2012. "A Mobile 3D-GIS Hybrid Recommender System for Tourism." Information Sciences 215: 37-52.

[17] Braunhofer, M., Elahi, M., and Ricci, F. 2011. "Context-Aware Places of Interest Recommendations for Mobile Users, Design, User Experience, and Usability." Theory, Methods, Tools and Practice, Lecture Notes in Computer Science 6769: 531-40.

[18] Ye, M., Yin, P., Lee, W. C., and Lee, D. L. 2011. "Exploiting Geographical Influence for Collaborative Point-of-Interest Recommendation." In Proceedings of the 34th International ACM SIGIR Conference on Research and Development in Information Retrieval, 325-34.

[19] Josh, J. C., Ying, E., Lu, H. C., Kuo, W. N., and Tseng, V. S. 2012. "Urban Point-of-Interest Recommendation by Mining User Check-in Behaviors." In Proceedings of the ACM SIGKDD International Workshop on Urban Computing, 63-70.

[20] Bao, J., Zheng, Y., and Mokbel, M. F. 2012. "Location-Based and Preference-Aware Recommendation Using Sparse Geo-Social Networking Data." In Proceedings of the 20th International Conference on Advances in Geographic Information Systems, 199-208.

[21] Yuan, Q., Cong, G., Ma, Z., Sun, A., and Thalmann, N.
M. 2013. "Time-Aware Point-of-Interest Recommendation." In Proceedings of the 36th International ACM SIGIR Conference on Research and Development in Information Retrieval, 363-72.

[22] Liu, X., Liu, Y., Aberer, K., and Miao, C. 2013. "Personalized Point-of-Interest Recommendation by Mining Users' Preference Transition." In Proceedings of the 22nd ACM International Conference on Information \& Knowledge Management, 733-8.

[23] Abe, S., Miki, D., and Yamamoto, K. 2017. "A Tourism Information System with Language-Barrier-Free Interfaces for Foreign Visitors." In Proceedings of the International Conference and Management (BEM) and International Conference on Marketing and Tourism, 58-66.

[24] Yanagisawa, T., and Yamamoto, K. 2012. "Study on Information Sharing GIS to Accumulate Local Knowledge in Local Communities." Theory and Applications of GIS 20 (1): 61-70.

[25] Nakahara, H., Yanagisawa, T., and Yamamoto, K. 2012. "Study on a Web-GIS to Support the Communication of Regional Knowledge in Regional Communities: Focusing on Regional Residents' Experiential Knowledge." Socio-Informatics 1 (2): 77-92.

[26] Yamada, S., and Yamamoto, K. 2013. "Development of Social Media GIS for Information Exchange between Regions." International Journal of Advanced Computer Science and Applications 4 (8): 62-73.

[27] Okuma, T., and Yamamoto, K. 2013. "Study on a Social Media GIS to Accumulate Urban Disaster Information: Accumulation of Disaster Information during Normal Times for Disaster Reduction Measures." Socio-Informatics 2 (2): 49-65.

[28] Murakoshi, T., and Yamamoto, K. 2014. "Study on a Social Media GIS to Support the Utilization of Disaster Information: For Disaster Reduction Measures from Normal Times to Disaster Outbreak Times." Socio-Informatics 3 (1): 17-30.

[29] Yamamoto, K., and Fujita, S. 2015. "Development of Social Media GIS to Support Information Utilization from Normal Times to Disaster Outbreak Times." International Journal of Advanced Computer Science and Applications 6 (9): 1-14.

[30] Ikeda, T., and Yamamoto, K. 2014. "Development of Social Recommendation GIS for Tourist Spots." International Journal of Advanced Computer Science and Applications 5 (12): 8-21.

[31] Mizutani, Y., and Yamamoto, K. 2017. "A Sightseeing Spot Recommendation System That Takes into Account the Change in Circumstances of Users." International Journal of Geo-Information $6 \quad$ (10): 303. doi:10.3390/ijgi6100303. 
[32] Jannach, D., Zanker, M., Felfernig, A., and Friedrich, G. 2011. Recommender Systems: An Introduction. UK: Cambridge University Press.

[33] Kamishima, T. 2008. "Algorithms for Recommender
Systems (2)." Transactions of Japanese Society of Artificial Intelligence 23 (1): 89-103.

[34] 4travel.jp. Accessed on 11 November 2017. http://4travel.jp/. 